\title{
Longitudinal predictions between temperamental sensitivities and achievement goal orientations in the early school years
}

\author{
Anna Maria Rawlings ${ }^{1}$ (D) Anna Tapola ${ }^{1}$ (D) $\cdot$ Markku Niemivirta ${ }^{1,2}$
}

Received: 23 July 2018 / Revised: 27 May 2019 / Accepted: 24 July 2019 /

Published online: 22 August 2019

(C) The Author(s) 2019

\begin{abstract}
Students' goal strivings are known to be connected with important outcomes, both academically and with regard to individual well-being. In spite of their importance, our knowledge of factors contributing to their early development is rather limited. In this longitudinal study on school beginners $(N=212)$, we focused on the interrelationships between achievement goal orientations (mastery; performance-approach; performance-avoidance; work-avoidance) and two temperamental sensitivities that appear relevant for the developing sense of mastery and performance in the school setting: interindividual reward sensitivity (reward derived from social approval and attention) and sensitivity to punishment (propensity to perceive cues of potential threat in the environment, and react with withdrawal and avoidance). The data were collected over the first three school years, from grade 1 (7-8 years) to grade 3 (9-10 years), and analysed using PLS-SEM. As expected, both temperamental sensitivities and achievement goal orientations remained relatively stable over time. Interindividual reward sensitivity was related negatively with mastery and positively with performance-approach and performanceavoidance orientations, from the first through to the third year. Punishment sensitivity had a positive effect on performance-avoidance orientation, and indirect, reciprocal, negative effects with performance-approach orientation. The findings provide new knowledge on early relationships between temperament and goal strivings. Interindividual reward sensitivity appears consistently associated with performance concerns and decreased mastery strivings. Such connections may have long-standing negative influence on students' educational trajectories, and point to the importance of acknowledging individual differences in temperament and their role in motivation and learning.
\end{abstract}

Keywords Motivation · Reward and punishment sensitivity · Follow-up study · Teacher-ratings · Elementary school

Anna Maria Rawlings anna.rawlings@helsinki.fi

Markku Niemivirta markku.niemivirta@helsinki.fi

Extended author information available on the last page of the article 


\section{Introduction}

Research focusing on students' preferences for certain kinds of goals in achievement-related settings (i.e. achievement goal orientations; Pintrich 2000) recognises individual differences in the tendency to approach desirable or avoid unwanted outcomes as an important defining characteristic (Elliot and Covington 2001). However, approach strivings can be differentiated further, based on whether one aims to develop one's skills and competence (i.e. mastery goals), or to demonstrate them by outperforming others (i.e. performance goals) (Dweck and Leggett 1988; Nicholls 1984). One of the key differences underlying the strivings is, then, whether success becomes defined in terms of self-referential (mastery) or other-referential (performance) standards. Achievement goal orientations have been found to influence several educationally relevant consequences, and to remain quite stable over time (for review, see Niemivirta, Pulkka, Tapola, \& Tuominen 2019). However, the factors influencing the emergence of different achievement goal orientations are, as yet, not well understood. The present study addresses this issue, by examining how temperamental sensitivities may contribute to their manifestation.

Temperamental reward and punishment sensitivities illustrate individuals' innate predispositions to focus either on appetitive (sensitivity to reward) or aversive (sensitivity to punishment) cues in the environment, and to react with approach or avoidance behaviour (e.g. Rothbart and Hwang 2005). Although these sensitivities are seen as universal, fairly stable interindividual differences are thought to exist in their relative strength, or the propensity for them (Corr, DeYoung, \& McNaughton 2013). Individuals differ also in what they perceive as signals of threat of punishment or possibility of reward (Corr 2013), and the same stimulus (e.g. the company of other people, Corr 2013; novelty, Carver and White 1994; Torrubia, Ávila, Moltó, \& Caseras 2001) can be perceived as either. For example, while less often considered as a separate reward dimension (for exception, see Colder et al. 2011), dependence on social approval and attention is nevertheless seen as an aspect of reward sensitivity, whereas sensitivity to punishment is linked with an aversion to being the centre of attention (e.g. through speaking in public, Colder and O'Connor 2004; Torrubia et al. 2001) and a tendency for social anxiety (Kingsbury, Coplan, Weeks, \& Rose-Krasnor 2013), especially in novel or unexpected situations (Torrubia et al. 2001).

Accordingly, it appears that both temperamental sensitivities and achievement goal orientations focus on individuals' approach and avoidance tendencies, and that aspects of social interaction may play a role in both, as a potential source of reward to be sought, or as something experienced as anxiety-inducing that may lead to the withdrawal behaviour that characterises punishment sensitivity. However, while temperamental sensitivities are thought to be innate propensities to react and behave in a certain way (e.g. Rothbart 2007), achievement goal orientations represent individuals' more flexible, acquired tendencies to select and prefer certain outcomes, which emerge and develop as a function of one's learning history and in interaction with the environment (e.g. Covington 2000; Nicholls, Patashnick, \& Nolen 1985; Shin and Ryan 2014). Consequently, as preceding their emergence over the course of an individual's development, temperamental sensitivities might be considered as guiding the propensity for adopting certain kinds of achievement goal orientations (e.g. Rothbart and Hwang 2005).

In line with this theorising, previous research has explored the relationships between approach and avoidance temperaments and goals (e.g. Bjørnebekk and Diseth 2010; Elliot and Thrash 2002). However, longitudinal research on these connections is sparse, and virtually non-existent during the early school years, and therefore, our aim is to add to this line of 
research by examining the early linkages of temperament and achievement goals over the course of the first three school years. The existing research has also mostly focused on a general sensitivity to rewarding stimuli (Bjørnebekk and Diseth 2010; Elliot and Thrash 2002, 2010), while in the present study, we operationalise reward sensitivity more in terms of reliance on social approval and attention, as these seem to incorporate cues relevant for the developing sense of mastery and performance in the school setting.

\section{Achievement goals and goal orientations}

The aim of understanding and explaining individuals' achievement behaviour in terms of their higher-order goals is the starting point of goal-theoretical perspectives on motivation (Nicholls 1989). Achievement goals have been viewed as task-specific and situational, and as more generalised orientations (for review, see Senko 2016). Both conceptualisations recognise a division into mastery and performance goals, and particularly performance goals are usually seen as separable further by an approach-avoidance distinction. Mastery goals describe the aim of learning, understanding, and skill improvement, and performance goals the aim of demonstrating ability (performance-approach) and avoiding exposing one's inabilities (performanceavoidance) (e.g. Elliot and Hulleman 2017). In addition to the mastery/performance distinction, also a third class of goals, work-avoidance, has been identified, which refers to a passive, indifferent attitude towards academic work and learning, with the aim of avoiding exerting any more than the minimum possible effort on it (Nicholls et al. 1985).

Generally, the adoption of a mastery goal or orientation has been found educationally adaptive, as they are connected with positive outcomes (e.g. persistence, Sideridis and Kaplan 2011; selfregulation, Cellar et al. 2011), whereas the opposite is true of both work-avoidance and performance-avoidance orientations, which have been found to be connected with, for example, disengagement from schoolwork (King 2014), lower grades and negative well-being (King and McInerney 2014), and maladaptive coping strategies (Skaalvik 2018) as well as negative affectivity, depression, and lower self-esteem (Sideridis 2005), respectively. The findings regarding performance-approach goals have been more mixed, as connections with both positive (e.g. academic success, for review, see Senko, Hulleman, \& Harackiewicz 2011) and negative (e.g. outcome concerns depleting working memory with subsequent impairment of cognitive performance, Crouzevialle and Butera 2013) outcomes have been discovered. Some recent studies suggest that these mixed connections may be explained by whether performanceapproach goals are operationalised as competence demonstration (so-called appearance goals) or as outperforming others (so-called normative goals), with appearance goals being associated with academically maladaptive, and normative goals with adaptive outcomes (e.g. Hulleman, Schrager, Bodmann, \& Harackiewicz 2010; Senko and Dawson 2017; Senko and Tropiano 2016). However, there have been calls for more research systematically testing this suggestion (Elliot and Hulleman 2017), and, importantly for the present study, we note the evidence for these differential effects is based on meta-analyses of the self-reports of considerably older students (see Senko and Dawson 2017). Hence, it remains as yet unclear whether very young students can differentiate between these two types of performance-approach goals, as well as whether their behavioural expressions would be discernibly different for an external observer.

Another line of research suggests that achievement goals may influence not only academic, but also social outcomes (e.g. Barrera and Schuster 2018; Darnon, Dompnier, \& Poortvliet 2012; Gonçalves, Niemivirta, \& Lemos 2017; Poortvliet and Darnon 2010; Shin and Ryan 2014). Here, too, endorsing mastery goals has mostly been found to be connected with positive outcomes 
(although cf. Poortvliet 2012), such as adaptive responding to unfavourable social comparison (Chatzisarantis, Ada, Bing, Papaioannou, Prpa, \& Hagger 2016) and being perceived by peers as more attractive cooperation partners and as having a higher social status (Barrera and Schuster 2018). In turn, performance-approach goals have been associated with maladaptive social behaviours (Poortvliet and Darnon 2010) and negative peer perceptions (Barrera and Schuster 2018), and performance-avoidance goals with lower likelihood of being named as a friend by peers (Shin and Ryan 2014).

Once adopted, achievement goal orientations have been found to remain relatively stable over time in both secondary and upper-secondary schools (Tuominen-Soini, Salmela-Aro, \& Niemivirta 2011) as well as during the early elementary years (Jõgi, Kikas, Lerkkanen, \& Mägi 2015; Mägi, Lerkkanen, Poikkeus, Rasku-Puttonen, \& Kikas 2010), although studies conducted during the early years remain relatively few. However, as yet, little is known about the factors influencing the emergence of a given orientation. Given their connections with both academically adaptive and maladaptive outcomes as well as the more general well-being of individuals, it appears a pertinent question for educational research to examine these factors, and thereby attempt to identify antecedents to their adoption.

\section{Temperamental reward and punishment sensitivities}

The sensitivities to avoid aversive (punishing) or seek appetitive (rewarding) stimuli are fundamental motivators of approach and avoidance behaviour, seen as stemming from innate individual differences in arousability or emotional reactivity (e.g. Corr 2013; Rothbart and Hwang 2005). These sensitivities are recognised in a number of theoretically similar and to some extent overlapping conceptualisations of temperament (for overview, see, e.g., Rothbart and Hwang 2005; Slobodskaya and Kuznetsova 2013), of which the behavioural inhibition and behavioural approach system (BIS/BAS; Gray and McNaughton 2003) and the approachavoidance temperaments (Elliot and Thrash 2002) appear particularly relevant to note in the present context, as both have been utilised in the relatively sparse previous research into the connections between temperament and students' achievement goals (Bjørnebekk 2007; Bjørnebekk and Diseth 2010; Elliot and Thrash 2002, 2010). Behavioural inhibition is seen as becoming activated when there is motivation to approach a potential reward, but potential danger is also perceived (DeYoung 2010), and is characterised by an anxious response of withdrawal or passive avoidance, whereas behavioural approach describes a propensity for one's attention being drawn to and focused on potential or actual rewards in the environment, and the active pursuit of these. ${ }^{1}$ Approach and avoidance temperaments, in turn, have been defined as general, neurobiological sensitivities to reward and punishment that are described, respectively, by behavioural approach, extraversion, and positive emotionality, and behavioural inhibition, neuroticism, and negative emotionality (Elliot and Thrash 2002).

Temperament is generally seen as relatively stable over time (e.g. Derryberry and Rothbart 1997; Gray and McNaughton 2003; Rothbart and Hwang 2005; Slobodskaya and Kozlova

\footnotetext{
${ }^{1}$ A third, fight-flight-freeze system (FFFS) is seen as governing reactions to fear experiences (e.g., Corr and Cooper 2016). However, it has been suggested that in the everyday experiences of most people, the kind of fear postulated as being governed by the FFFS is rare, whereas anxiety and subsequent withdrawal or passive avoidance, brought on by conflicting goals and related experiences of threat, is fairly commonplace (DeYoung 2010). As the present research deals with elementary-school students in their everyday learning environment, it appears well-reasoned as well as in keeping with previous research (e.g., Slobodskaya and Kuznetsova 2013; Torrubia et al. 2001) to focus here on sensitivity to punishment and sensitivity to reward.
} 
2016), with some findings showing an amount of stability from infancy onwards (Carranza, González-Salinas, \& Ato 2013), although longitudinal research into reward and punishment sensitivities is somewhat sparse. Behavioural inhibition (Bishop, Spence, \& McDonald 2003; De Decker et al. 2017) and a dimension of behavioural approach describing drive and persistence (De Decker et al. 2017) have been reported to exhibit normative stability (i.e. the preservation of individual ranks on a quality; Kagan 1980) in childhood, as have approach and avoidance temperaments among university students (Elliot and Thrash 2010). Reward sensitivity has also been observed to increase from early to late adolescence and early adulthood (Urošević, Collins, Muetzel, Lim, \& Luciana 2012).

People differ in what they perceive as threatening or rewarding (Corr 2013), and sensitivities to different kinds of reward, such as dependence on social acceptance or novelty-seeking (Cloninger, Svarkic, \& Przybeck 1993), have been proposed. Individual differences in the strength of certain neurobiological indicators have been found to predict individuals' selfevaluations in these two reward sensitivities (Cohen, Weber, Schoene-Bake, \& Elger, Cohen 2009), giving an indication of their deep-rooted nature. However, reward derived from social approval and attention has often been either left unconsidered in scales measuring temperament (Carver and White 1994) or has been included as part of a more general construct of sensitivity to reward (Torrubia et al. 2001), although the desire for praise, approval, and making a good impression on others has also been empirically observed to form a distinct reward dimension (Colder et al. 2011).

Research examining the connections between reward and punishment sensitivity and students' goal pursuits has not, to our knowledge, utilised a multi-dimensional conceptualisation of reward sensitivity, and the interindividual aspect of reward sensitivity remains quite overlooked, even though students' everyday classroom experiences are largely based on social interactions (e.g. Barrera and Schuster 2018; Shin and Ryan 2014), in which it is likely to become activated. Different kinds of novel, unexpected, and public social situations may also activate sensitivity to punishment and lead to withdrawal and avoidance behaviour (Torrubia et al. 2001). These kinds of experiences and perceptions in the early school years may influence, among other things, the emergence and establishment of long-lasting motivational orientations.

\section{Connections between reward and punishment sensitivity and achievement goal orientations}

Since temperamental sensitivities influence motivated behaviour (e.g. Rothbart and Hwang 2005), it is plausible that they, in interaction with the individual's environment (see, e.g., Roubinov, Hagan, Boyce, Essex, \& Bush 2017), also guide the adoption of achievement goal orientations. As explicated above, reward sensitivity as well as mastery and performanceapproach orientations are characterised by the approach tendency, and punishment sensitivity and performance-avoidance orientation by the tendency to avoid or withdraw from perceived threat (e.g. Elliot and Covington 2001; Elliot and Thrash 2002). However, the aspect of reward sensitivity describing reliance on social approval and attention (Colder et al. 2011; Torrubia et al. 2001) appears conceptually more connected with both performance-approach and performance-avoidance orientations than with mastery orientation, as in the performance orientations, successful goal attainment is dependent on other people, whereas in mastery orientation, it is not (e.g. Senko 2016). There also appears to be a parallel between the discomfort with and withdrawal from novel situations and performing in public associated with punishment sensitivity (e.g. Bishop et al. 2003; Colder and O'Connor 2004; Torrubia et al. 2001) and 
the focus on and avoidance of potential public failure that differentiates performanceavoidance orientation from performance-approach (e.g. Elliot and Thrash 2001). Workavoidance orientation is to our knowledge unexamined in previous research into the connections between temperament and goal strivings. Although it is possible that it is less related with temperamental sensitivities and more with other motivational factors, such as value beliefs (Tuominen-Soini, Salmela-Aro, \& Niemivirta 2012), its connections to social factors, such as peer influence and teacher support (King and McInerney 2014), makes it relevant in the present context as well.

In everyday classroom situations, these connections may mean, for example, that social "success" (e.g. being the centre of attention or outperforming others) represents something to be sought for some students, whereas others may interpret similar, fairly commonplace social interactions (e.g. involving competition or having to speak in front of others) differently and perceive them as a threat to be avoided (e.g. Corr 2013; Derryberry and Rothbart 1997; Tapola and Niemivirta 2008).

Previous research examining the relationship between temperament and achievement goals has utilised the approach and avoidance temperament and BIS/BAS conceptualisations. Due to their conceptual relatedness and partial overlap with reward and punishment sensitivity, the obtained results seem relevant to consider here. Approach temperament and BAS have been found to be connected with mastery-approach and performance-approach goals in both pre-teens (Bjørnebekk 2007; Bjørnebekk and Diseth 2010) and university students (Elliot and Thrash 2002, 2010), whereas avoidance temperament and BIS have been found to be linked with mastery-avoidance and performance-avoidance goals (Bjørnebekk 2007; Bjørnebekk and Diseth 2010; Elliot and Thrash 2002, 2010). These results, however, have not been entirely straightforward, for avoidance temperament has also been found to predict performance-approach goals (Bjørnebekk and Diseth 2010; Elliot and Thrash 2002), and BAS to predict performance-avoidance goals (Bjørnebekk 2007), prompting questions regarding the potential mechanisms behind goal adoption, including a posited approach-to-avoid tactic (Elliot and Thrash 2001). We suggest that viewing reward derived from social approval and attention as a separate reward dimension and examining its influence on goal adoption may increase and support understanding of these relations.

In previous research, this sensitivity to social approval and attention has been conceptualised as interindividual reward sensitivity (Rawlings, Tapola, \& Niemivirta 2017), and found positively related to work-avoidance and negatively to mastery-intrinsic orientation (i.e. the goal of improving one's skills, developing competence, and deepening understanding, Niemivirta 2002), in contrast to related constructs (approach temperament; BAS) usually being found positively related to mastery strivings (Bjørnebekk 2007; Bjørnebekk and Diseth 2010; Elliot and Thrash 2002, 2010). These related constructs have not, however, explicitly included sensitivity to reward from attention or approval, in particular not as an independent dimension. In addition to this, it is also interesting that although interindividual reward sensitivity and punishment sensitivity differ considerably from each other (e.g. punishment sensitivity induces an aversion to being the centre of attention, which is a central source of interindividual reward), their effects were found to resemble each other in that both predicted performanceapproach and performance-avoidance orientations positively. Based on this, it would appear that both of these sensitivities might, in spite of their differences, be involved in the adoption of performance-related goal orientations, which, in turn, have often been found less adaptive both academically and from the point of view of subjective well-being (e.g. Crouzevialle and Butera 2013; Skaalvik 2018) as well as socially (e.g. Barrera and Schuster 2018; Shin and Ryan 2014). The role of experiences within the social environment, such as being centre of attention, 
appears important for both sensitivities, although reactions to it may be polar opposites (i.e. withdrawing from or being drawn to it).

In sum, examining the connections between reward and punishment sensitivities and goal adoption seems fruitful, the mechanisms of goal adoption are likely to be complex, and including social attention and approval as a source of reward may be helpful. Further, we are not aware of any studies examining interrelationships of temperamental sensitivities and achievement goal orientations over time. Also, the cross-sectional research on these connections has been conducted among university students (Elliot and Thrash 2002, 2010) or preadolescent students approaching secondary school (Bjørnebekk 2007; Bjørnebekk and Diseth 2010), but research during the first school years is lacking. Further study on these connections is therefore clearly needed. It appears particularly important to examine whether some temperamental sensitivities contribute towards the adoption of educationally maladaptive goal orientations. As these appear to become fairly stable early on, some students may become disadvantaged from the first school years onwards. An increased understanding of how motivational orientations develop would further existing knowledge, as well as potentially contribute towards developing educational practices that support learners of all temperamental sensitivities.

\section{Present study}

The aim of the present research was to examine the stability and predictive relationships between achievement goal orientations and temperamental sensitivities, namely, interindividual reward sensitivity (i.e. reward derived from social approval, e.g. praise or attention) and punishment sensitivity, over the first three school years.

Innate temperamental sensitivities to reward and punishment are considered important motivators of approach and avoidance behaviour (Corr 2013; Rothbart and Hwang 2005), and the approach/avoidance distinction is also a central concept in research into motivation, particularly goals (e.g. Elliot and Covington 2001). While less noted as a separate reward dimension (for exception, see Colder et al. 2011), reward derived from social approval and attention is nevertheless recognised in research into temperamental sensitivities (Colder and O'Connor 2004; Torrubia et al. 2001). Similarly, the dependence or independence of goal attainment on the actions and reactions of others is an element that differentiates between types of achievement goal orientations. In addition to these conceptual connections, previous empirical research has observed links between temperament and goal strivings (Bjørnebekk 2007; Bjørnebekk and Diseth 2010; Elliot and Thrash 2002, 2010). Interindividual reward sensitivity and sensitivity to punishment have been found connected with more maladaptive goal orientations (Rawlings et al. 2017), and therefore, in the present study, we focused on these sensitivities.

We operationalised interindividual reward sensitivity as referring to sensitivity to reward from an external source (i.e. other people), expressed behaviourally in the form of seeking attention and/or praise and to impress others, based on previous research (Colder and O'Connor 2004; Torrubia et al. 2001; see also, Colder et al. 2011). Sensitivity to punishment was operationalised as timidity and withdrawal from novel, unexpected, or otherwise difficult situations and an avoidance of failure, likewise based on previous research (Carver and White 1994; Cloninger et al. 1993; Colder and O'Connor 2004; Rothbart 2007; Torrubia et al. 2001). 
As to the assessment, it has been noted that even older students than our participants have difficulties evaluating their responses regarding complex dispositional tendencies (Bong, Woo, \& Shin 2013), and using children's self-ratings of personality has even been entirely discouraged (Poropat 2014). More importantly, our data collection began in the spring of the first grade, when Finnish school children are not yet expected to know how to read. Consequently, to enable commensurate ratings across the three years of data collection, and as using teacherevaluation has been considered valid for assessing children's temperament (e.g. Bishop et al. 2003; Hirvonen, Aunola, Alatupa, Viljaranta, \& Nurmi 2013) as well as motivational tendencies (e.g. Hirvonen, Torppa, Nurmi, Eklund, \& Ahonen 2016; Lepola 2004), it was deemed appropriate for the present research. Given the observer point of view, the wording of the items was slightly modified from those used previously for adolescents' and adults' self-evaluations, to describe behavioural responses rather than personal experiences.

Regarding achievement goal orientations, we utilised a similarly modified version of an instrument (Niemivirta 2002) much used in previous research, until now mainly with older students (for review, see Niemivirta et al. 2019). In the measure, in addition to the overall division into mastery, performance, and work-avoidance orientations (Nicholls et al. 1985), the performance orientation is separated further into an approach and avoidance dimension, as is common in achievement goal research (e.g. Elliot and Thrash 2002; Sideridis and Kaplan $2011){ }^{2}$ With regard to the recent suggestion of distinguishing appearance vs. normative performance-approach goals (e.g. Hulleman et al. 2010; Senko and Dawson 2017; Senko and Tropiano 2016), the observer point-of-view restricts us to assessing goals from their behavioural expression. Additionally, the age of the participating students may further complicate making very fine-tuned distinctions. Therefore, in the present research, we follow the "goal orientation tradition" (see Senko and Tropiano 2016), in other words, view the performance-approach goal orientation as representing the higher-order goal of demonstrating competence by outperforming others, expressed behaviourally as wanting to appear more able than others and openly comparing one's skills with those of others. In a similar vein, we see the performance-avoidance goal orientation as representing the higher-order goal of avoiding demonstrating a lack of competence that is behaviourally expressed as not wanting to appear stupid or incapable, and as visibly worrying about this happening (i.e. worrying about doing less well than others).

Consequently, four orientations were measured, namely, mastery orientation describing the goal of learning for the sake of itself (i.e. improving one's skills, developing competence, deepening understanding); performance-approach orientation entailing the goal of demonstrating competence by outperforming others; performance-avoidance orientation with the goal of avoiding being seen as incompetent or failing; and work-avoidance orientation with the aim of avoiding effort expenditure and completing only the compulsory minimum of tasks.

We expected to find relatively high normative stability in both temperamental sensitivities and achievement goal orientations. We anticipated interindividual reward sensitivity to predict mastery orientation negatively and performance-approach, performance-avoidance, and workavoidance orientations positively. These expectations are based on previous work (Rawlings et al. 2017), although given the considerably younger age of the participants in the present

\footnotetext{
${ }^{2}$ The original version recognises intrinsically and extrinsically driven dimensions of mastery, but given the young age of the students, and the external, formal criteria of learning (e.g., grades) being virtually absent in the Finnish educational system during these first years of school, we considered mastery here as a one-dimensional construct.
} 
research, they remain fairly tentative. We assumed sensitivity to punishment to predict performance-avoidance orientation positively, in line with previous research (Bjørnebekk and Diseth 2010; Elliot and Thrash 2002). As to its relationship with performance-approach orientation, a negative prediction seems theoretically meaningful (temperamental sensitivity to avoid rather than approach situations where failure is possible), but positive, "approach-toavoid" predictions (i.e. student strives to approach success so as to avoid failure) have sometimes been observed among pre-adolescents (Bjørnebekk and Diseth 2010) and university students (Elliot and Thrash 2002; Rawlings et al. 2017). As the participants in our study are much younger, we refrained from setting an expectation on this relationship.

\section{Method}

\section{Participants and procedure}

The participants were students $(N=212,51.5 \%$ girls $)$ from 17 classes in six schools in the metropolitan area in Finland. All in all, 25 class teachers evaluated their students' temperamental sensitivities and achievement goal orientations using an online questionnaire, in the spring of the first, second, and third grades, when the students were aged 7-8 years, 8-9 years, and 9-10 years, respectively. ${ }^{3}$

Teacher evaluations were received on 232 students in the first year, 197 in the second year, and 188 in the third year, amounting to 142 students having teacher evaluations from all three years, 212 students from at least two years, and 262 students from at least one year. In order to optimise the number of participants in the analyses and minimise loss of data, we chose to include all students with data from at least two measurement points. ${ }^{4}$ As the attrition was found not selective and the imputation valid, our final sample included 212 students. $^{5}$

All participating schools were in middle-class, largely ethnically Finnish areas of the city. Participation was voluntary, written consent was given by parents, and confidentiality was assured.

\section{Measures}

Sensitivity to punishment (SP; 5 items, e.g. "The child behaves timidly in new or unexpected situations") and sensitivity to interindividual reward (SR; 5 items, e.g. "The child often does things (e.g., extra school work) simply to be praised") were measured on a Likert-type scale of

\footnotetext{
${ }^{3}$ In Finnish elementary schools, each class has an allocated class teacher who teaches most subjects to their class and, whenever possible, stays with them from the first through to the sixth grades, after which students move to secondary school (Finnish National Agency for Education 2017). In this study, 98\% of the evaluations were given by the same teachers in the second as in the first grade, and around $60 \%$ in the third grade as in the second. Note that the percentage of change in teachers evaluating the students is not directly equivalent to a change in class teachers as such, as some classes had two class teachers, who completed the evaluation in different years. ${ }^{4}$ Of the students $(N=212)$ included in the present study, 18 had teacher evaluations from the first and third years, the rest being from consecutive years. Among the students who provided data for only one year $(n=33$ in year 1 , $n=2$ in year 2 , and $n=15$ in year 3 ), those who dropped out after t 1 reported slightly lower $(p<.05)$ reward sensitivity and mastery orientation.

${ }^{5}$ To check the stability of our results, we ran three sets of analyses: (1) with $N=142$; (2) with $N=212$; and (3) with $N=262$, imputing the missing values, where appropriate. The results remained stable across the three sets of analyses, with only some slight differences mainly due to the variation in statistical power.
} 
1 "hardly ever" to 4 "very often", using a previously validated instrument (Rawlings et al. 2017) modified to enable observer- rather than self-evaluations, utilising items from previous research (Carver and White 1994; Cloninger et al. 1993; Colder and O'Connor 2004; Rothbart 2007; Torrubia et al. 2001). Achievement goal orientations were measured using a similarly modified version of an instrument (Niemivirta 2002) extensively used in previous research (see, e.g., Niemivirta et al. 2019). Four dimensions of achievement goal orientations, namely, mastery (e.g. "Learning and understanding are visibly important for the child"); performanceapproach (e.g. "It is important for the child to do better than other students"); performanceavoidance (e.g. "The child is clearly afraid they'll do worse than others"); and work-avoidance (e.g. "The child tries to take the easy way out"), were measured on a Likert-type scale of 1 "not true at all" to 4 "very true", with two items per orientation. All items are given in Table 1.

\section{Analyses}

The data were analysed using Partial Least Lquares structural equation modeling (PLS-SEM). PLS-SEM is considered a viable alternative to CB-SEM when running a complex model on data with a small numerus (Sarstedt, Ringle, \& Hair 2017), as it does not impose strict distributional assumptions on data (Sanchez 2013). ${ }^{6}$ We used the "plspm" package (Sanchez, Trinchera, \& Russolillo 2015) with R software version 3.2.3, with a centroid weighting scheme for estimating inner weights, and a bootstrapping procedure with 500 bootstrap samples for estimating parameter significance. Missing values were imputed using the "missForest" package (Stekhoven 2013), an iterative imputation method using a random number generator that has been shown to perform well also in data settings with complex interactions and non-linear relations (Stekhoven and Bühlmann 2011).

Unlike CB-SEM, PLS-SEM does not have a straightforward goodness-of-fit index (Hair Jr, Hult, Ringle, \& Sarstedt 2014). Rather, various evaluation criteria are considered together, to assess the model. Internal consistency reliability is evaluated using composite reliability (values .60-.70 considered adequate for exploratory research; Hair Jr et al. 2014). Convergent validity is checked using indicator loadings, which should be significant and greater than .7, and average variance extracted (AVE), which should be above .5 (Hair Jr et al. 2014). However, regarding indicator loadings, recommended practice is to remove indicators with a loading between .40 and .70 only if removing the item results in an increase of either the composite reliability or the AVE above the threshold values (Hair Jr et al. 2014). To establish discriminant validity, the loadings of indicators on their intended constructs should be greater than their crossloadings on other constructs, and the square root of the AVE of each latent variable should be higher than its correlation with other latent variables (Fornell-Larcker criterion; Hair Jr et al. 2014).

\footnotetext{
$\overline{{ }^{6}}$ Note that analyses were also run in the covariance-based structural equation modeling (CB-SEM) framework, including initial testing for factorial invariance and correlated residuals over time with exploratory structural equation modeling, which gave an adequate fit, $\chi^{2}(1186)=1956.268, p<.001$; RMSEA .055, CFI = .916. Due to the fairly complex model, examining the predictive relationships between latent factors in the CB-SEM framework through a cross-lagged panel model was somewhat inappropriate. However, running the cross-lagged panel model in CB-SEM with single-item latent variables (formed from composite scores) with both $N=262\left(\chi^{2}\right.$ $(65)=150.081, p<.001 ;$ RMSEA $.071, \mathrm{CFI}=.954, \mathrm{SRMR}=.077)$ and $N=212\left(\chi^{2}(65)=142.285, p<.001\right.$; RMSEA $.075, \mathrm{CFI}=.956$, SRMR $=.079)$ gave almost identical results to the predictive effects we report here, obtained using full item-level information in PLS-SEM. Unfortunately, the number of teachers and class sizes were not large enough for appropriately running the analyses with an estimation method that takes into account the possible clustering effect.
} 
Table 1 Bootstrapped factor loadings of all latent variables

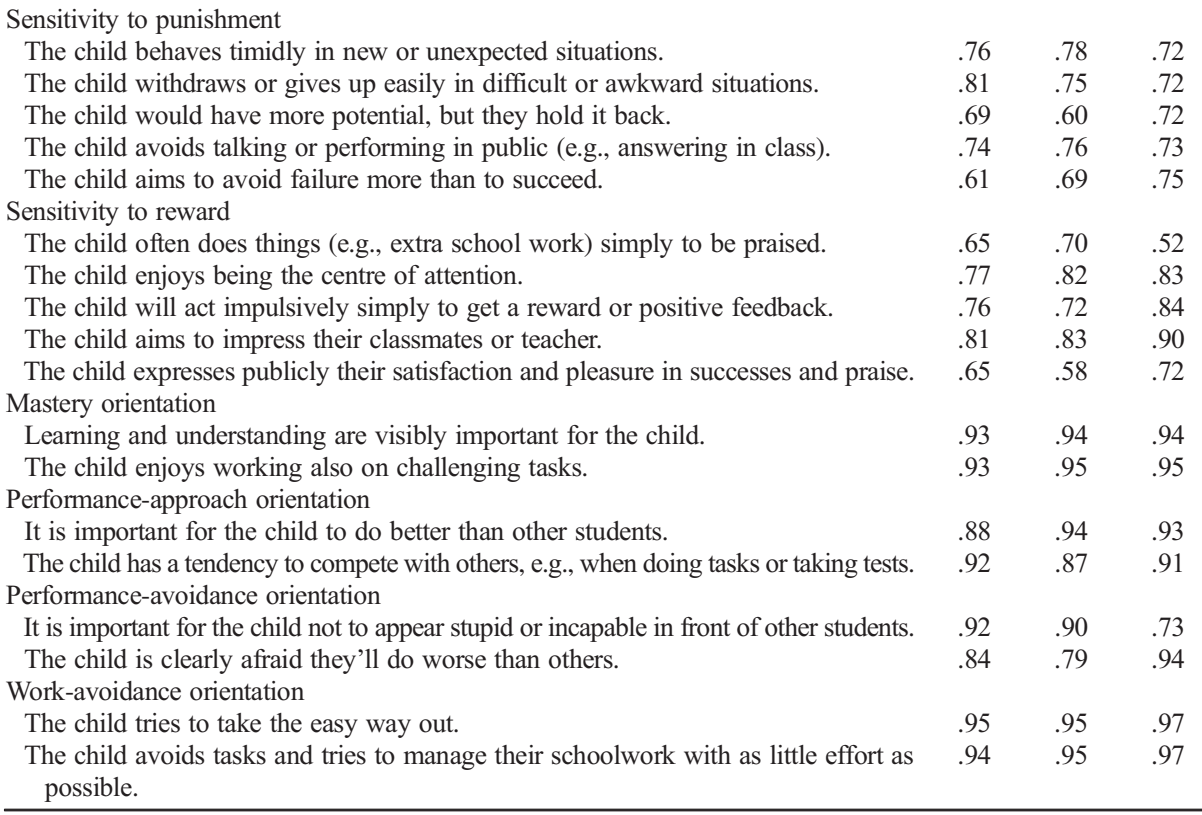

All factor loadings are significant at $95 \% \mathrm{CI}$

A measurement model based on theoretical considerations was specified, with items defined as loading on their respective latent factors (SP; SR; mastery, performance-approach, performance-avoidance, work-avoidance orientations) at each of the three measurement points. Regarding the structural model, as the developmental connections between the behavioural manifestation of temperamental sensitivities and motivational tendencies could be assumed to be cyclical rather than unidirectional in nature (see Rothbart and Hwang 2005), and as previous research does not offer direct evidence for causal predominance, we estimated the effects as reciprocal. Consequently, each construct (temperamental sensitivities as well as achievement goal orientations) at the third measurement point (t3) was regressed on each construct at the second measurement point (t2), and similarly each construct at $\mathrm{t} 2$ on each construct at the first measurement point (t1). The model specified is illustrated in Fig. 1.

The factor structure of the specified measurement model was examined. All indicator variables had loadings $>.50$ on their intended latent variables, with the majority being $>.70$ (see Table 1). One SP item had a high crossloading at t1, but as this reduced considerably at subsequent measurement points, and as at all time points, the Dillon-Goldstein's (DG) $\rho$ composite reliability value was $>.80$, AVE $>.50$, and the Fornell-Larcker criterion was met, no items were removed, as recommended by Hair et al. (Hair Jr et al. 2014). Discriminant validity was also established using the heterotrait-monotrait (HTMT) inference criterion (Henseler, Ringle, \& Sarstedt 2015). Multicollinearity was checked using the variance inflation factor (VIF), the value of which remained below the threshold of 5. Descriptive statistics, DG $\rho$ values, and latent variable correlations are given in Table 2. 


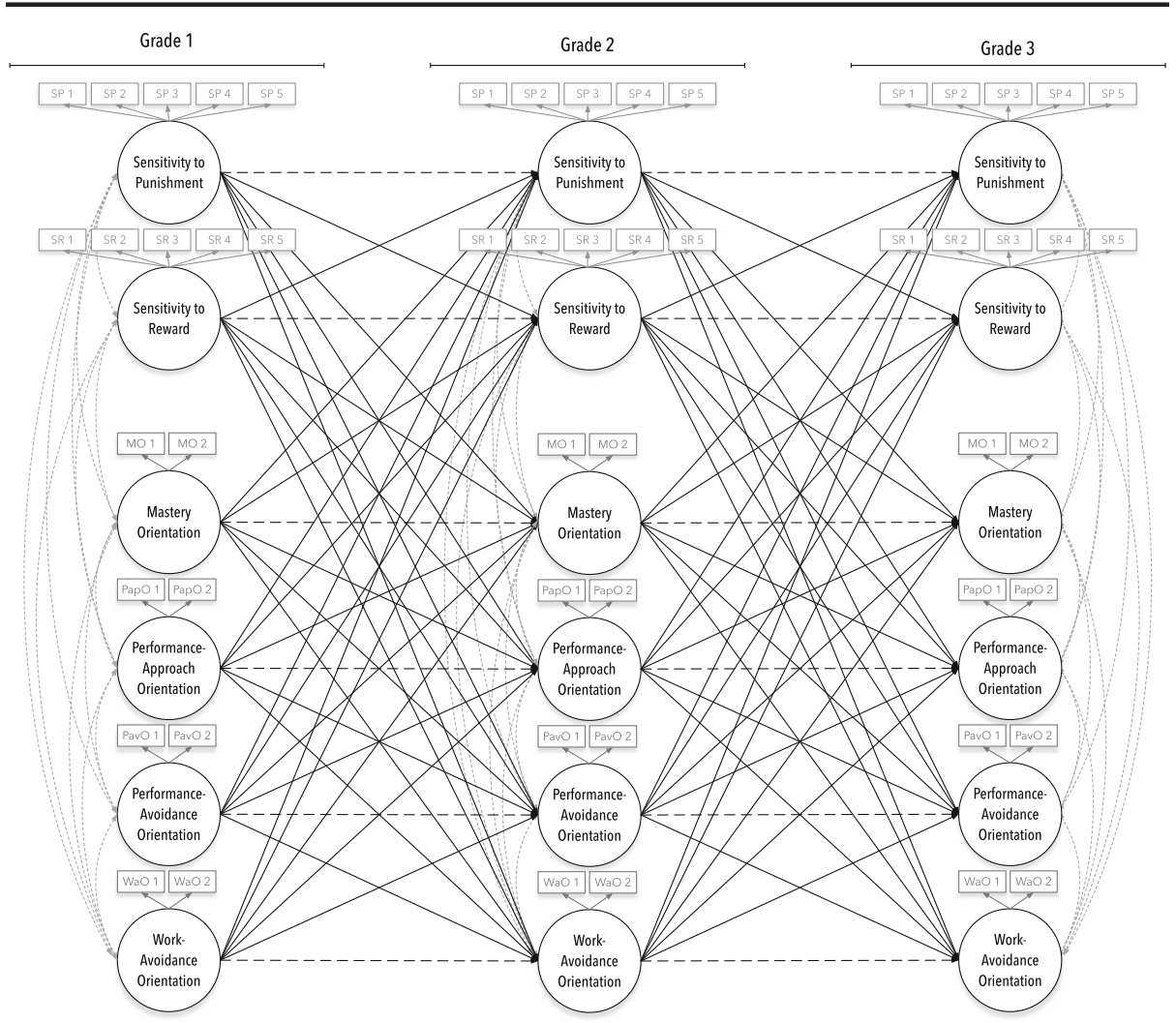

Fig. 1 The longitudinal cross-lagged panel model to be estimated. Correlations are shown with dotted, autoregressive effects with dashed lines

\section{Results}

The structural model significantly explained the variance of all endogenous variables, with the $R^{2}$ values ranging from .29 (performance-avoidance orientation in the second year) to .57 (work-avoidance orientation in the second year). The explained variance of all dependent variables and all predictive effects, with significance levels indicated with $95 \%$ confidence intervals (CI), is given in Table 3 .

Both temperamental sensitivities and all achievement goal orientations exhibited normative stability, with all autoregressive effects significant at 95\% CI and the stabilities of temperamental sensitivities ranging between $\beta=.53$ (sensitivity to reward between $\mathrm{t} 1$ and $\mathrm{t} 2$; sensitivity to punishment between $\mathrm{t} 2$ and $\mathrm{t} 3$ ) and $\beta=.59$ (sensitivity to reward between $\mathrm{t} 2$ and $\mathrm{t} 3$ ), and of achievement goal orientations between $\beta=.25$ (performance-avoidance orientation between $\mathrm{t} 1$ and $\mathrm{t} 2$ ) and $\beta=.63$ (performance-approach orientation between $\mathrm{t} 1$ and $\mathrm{t} 2$ ).

Some interesting asymmetrical patterns of reciprocal effects were observed. First, SR in the first year negatively predicted change in mastery orientation in the second year, which, in turn, negatively predicted change in SR in the third year. Second, there was a similar, but positive, asymmetrical reciprocal effect between performance-approach 


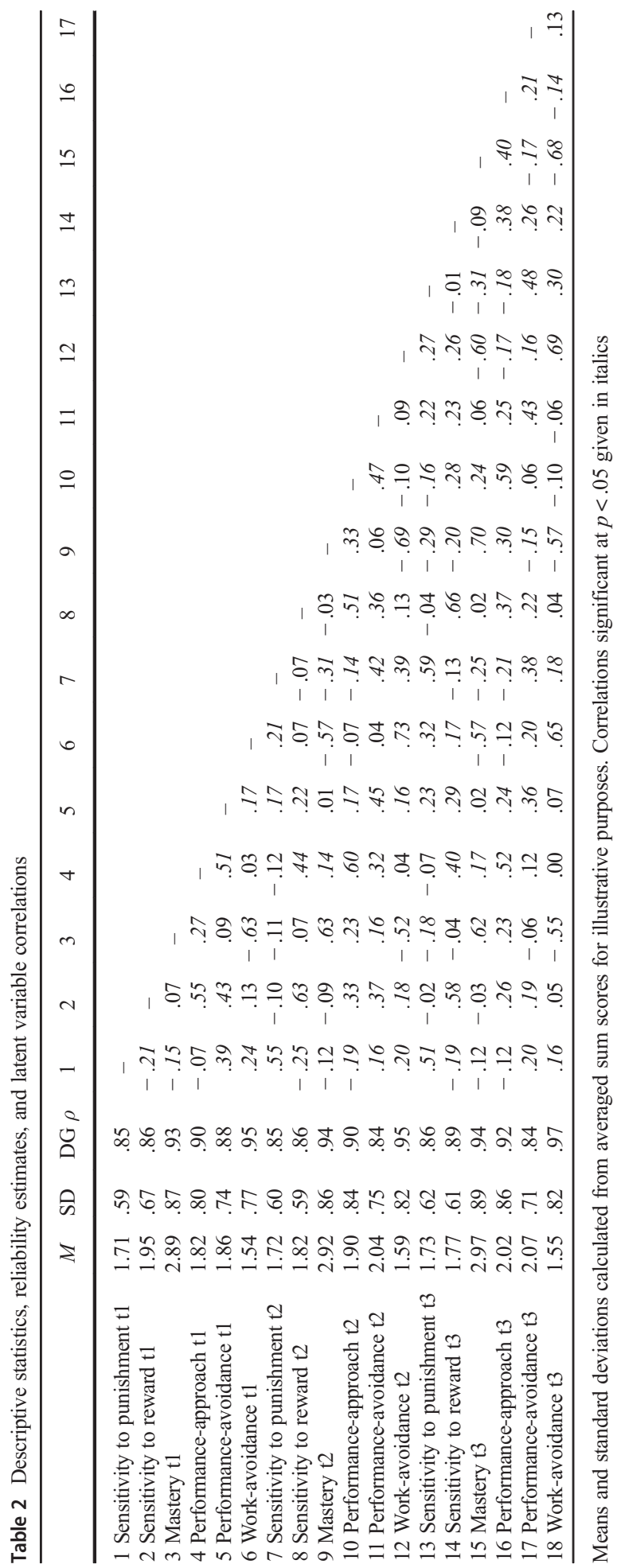




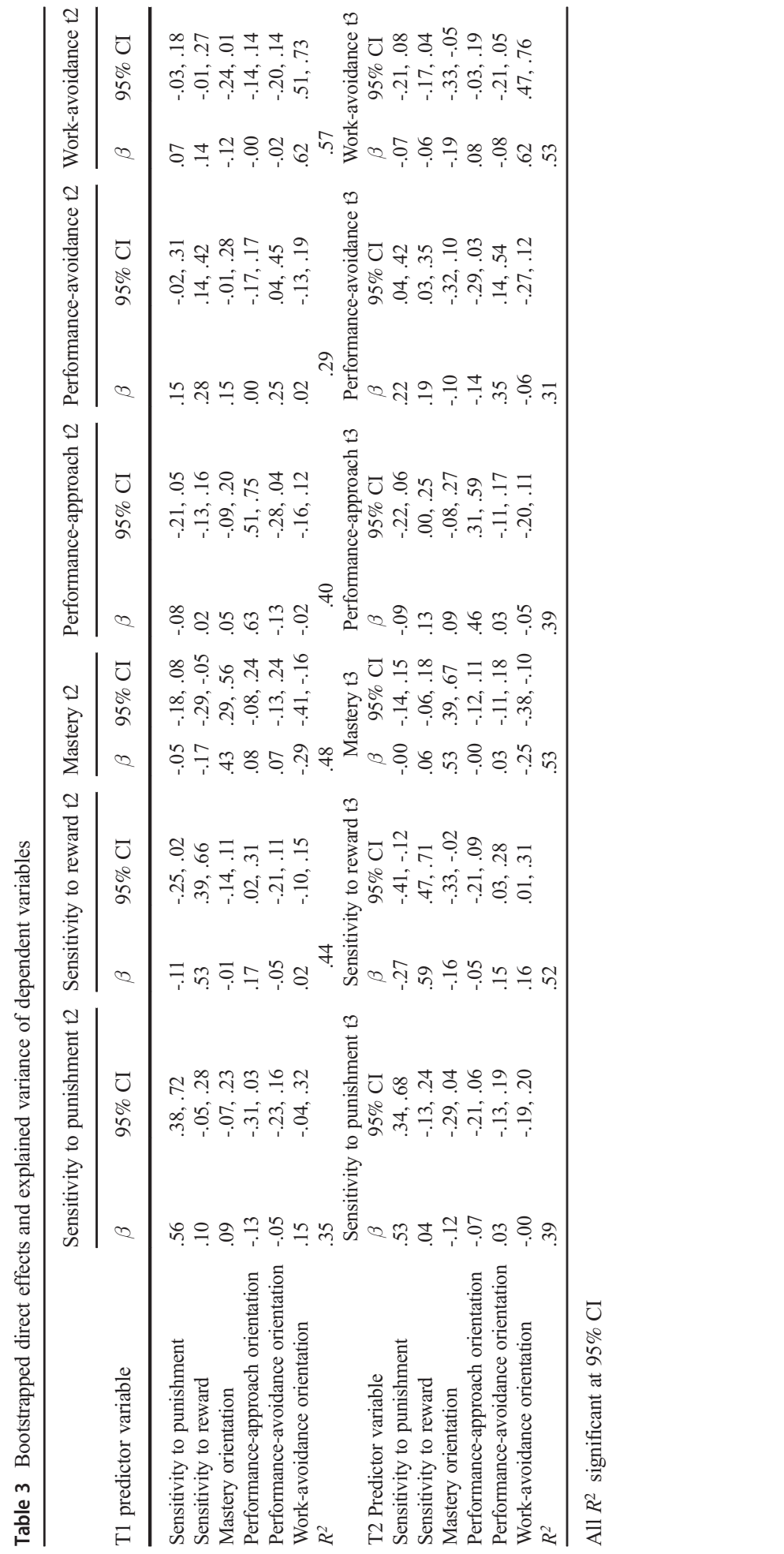


orientation and SR. Third, SR in the first year also positively predicted change in performance-avoidance in the second year, and in the third year, the relationship was reciprocal, so that SR and performance-avoidance both positively predicted change in each other. Fourth, there were similar, sequential, and in part reciprocal predictions between work-avoidance and mastery orientations, so that work-avoidance orientation in the first year negatively predicted change in mastery orientation in the second year, and both orientations negatively predicted change in each other in the third year. In addition to these reciprocal effects, change in SR in the third year was predicted negatively by SP and positively by work-avoidance orientation in the second year, and in performance-avoidance orientation in the third year positively by SP in the second year. All significant effects are illustrated in Fig. 2.

Some indirect effects were also observed. SP and performance-approach orientation in the first year negatively predicted change in each other in the third year, although no direct effects were observed between them. Mastery and work-avoidance orientations in the first year negatively predicted change in each other in the third year. Change in SR in the third year was negatively predicted by SP and positively by work-avoidance orientation in the first year, and change in performance-avoidance in the third year positively by both SP and SR in the first year. All indirect effects are given in Table 4.

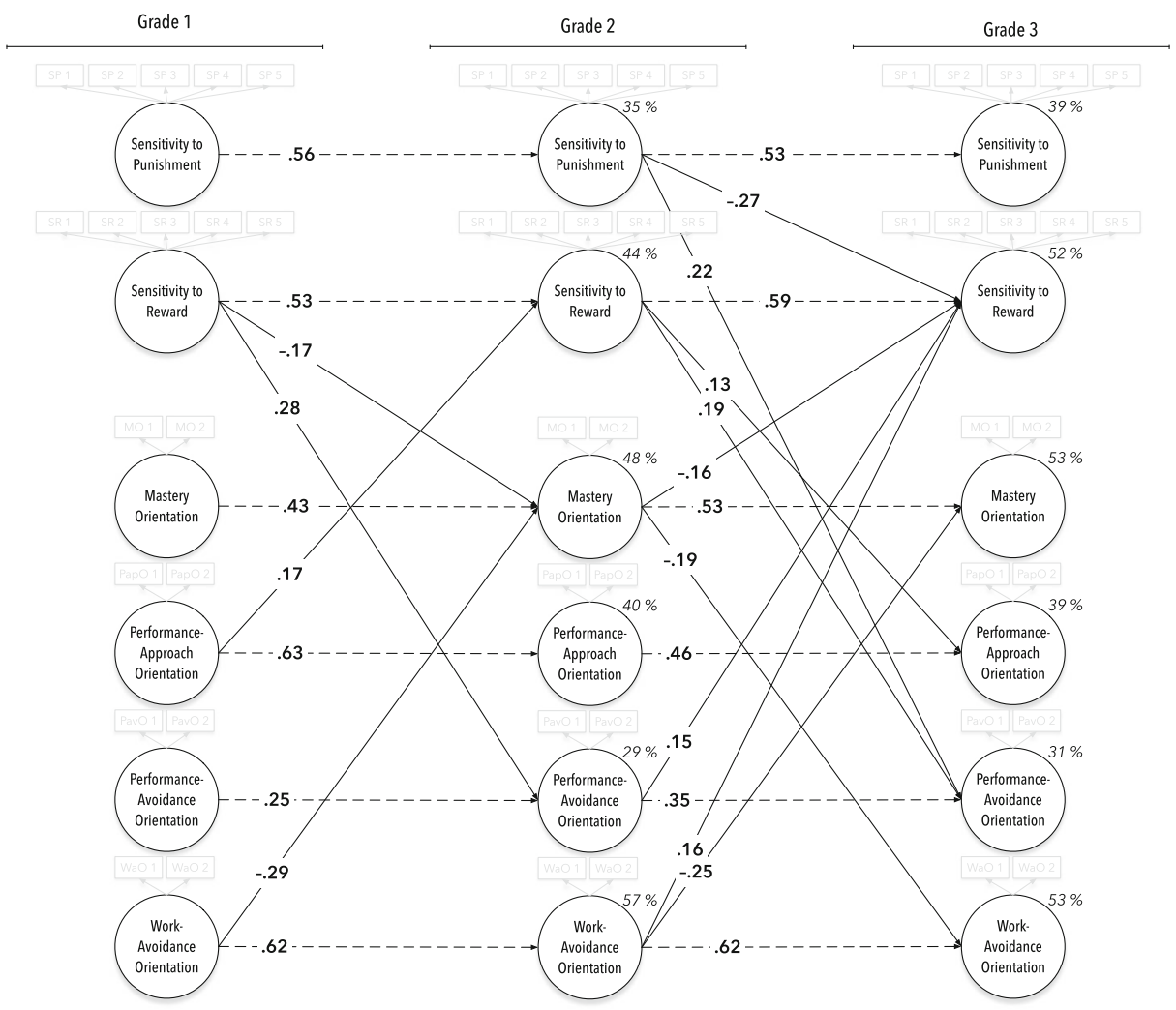

Fig. 2 Results of PLS-SEM analysis illustrated. For clarity, factor loadings of observed variables and correlations of latent variables are omitted, and only significant (CI 95\%) effects $(\beta)$ are reported. Autoregressive effects are shown with dashed lines 


\section{Discussion}

The purpose of this study was to examine the stability of and predictive interrelationships between sensitivity to punishment and sensitivity to interindividual reward and achievement goal orientations, over the course of the first three school years. As expected, both temperamental sensitivities and all achievement goal orientations exhibited relatively high normative stability over time. With regard to temperamental sensitivities, this reflects previous results where (mother-rated) punishment sensitivity and motivated behaviour for pursuit of rewarding goals remained relatively unchanged over a two-year period (De Decker et al. 2017). The stability of achievement goal orientations is in line with children's self-evaluations reported in previous research (Jõgi et al. 2015; Mägi et al. 2010), although the stability of performanceavoidance orientation in the present research was somewhat lower than the stability of the other orientations and temperamental sensitivities.

Regarding the predictive relationships between temperamental sensitivities and achievement goal orientations, the results mostly supported our tentative assumptions, thus suggesting that students' temperamental sensitivities and motivational tendencies become quite consistently linked in teachers' evaluations, already from an early age onwards. As assumed, interindividual reward sensitivity had a negative relationship with mastery, and positive with performance-approach, performance-avoidance, and work-avoidance orientations. Apart from work-avoidance orientation, the observed relationships were asymmetrically or fully reciprocal. As noted earlier, the reciprocity of the effects should not be interpreted as implying strict causality, but should, rather, be seen as an empirical prediction that illustrates the cyclic nature of the (teacher-interpreted) behavioural manifestations of the students' sensitivities and tendencies, and reflects their individual ways of behavioural regulation and adjustment to the school context. The observed connections are in line with previous findings (Rawlings et al. 2017), and suggest that already at a young age, high levels of the need for praise and/or attention from others may distract students from the enjoyment of learning and may, instead, introduce performance concerns and work-avoidance. One possible reason might be attentional bias (Derryberry et al. 2003). That is, if the sensitivity to social approval and attention is high, a student may define the desired end result as gaining positive or avoiding negative attention also in educational settings. As a consequence, the student's focus in learning situations might be on the outcome (i.e. performance as a means to gain social approval or attention) instead of the task or learning itself, and the possibility of failing to reach the goal makes the student more vulnerable to worry, negative affect, and concerns over the adequacy of their performance. In other words, the self is at stake.

The connections observed here between sensitivity to interindividual reward and the performance orientations also appear notable in light of recent research linking performanceapproach goals with maladaptive social behaviours (for review, see Poortvliet and Darnon 2010), and both performance-approach (Barrera and Schuster 2018) and performanceavoidance (Shin and Ryan 2014) goals with more negative peer perceptions. The mechanisms that may underlie a development from being sensitive to or needing others' praise and attention to perceiving (and, perhaps, being perceived) and treating them as adversaries remain beyond the scope of the present study, but appear worthwhile of further examination in future studies.

As to sensitivity to punishment, although it remained less connected with the other constructs than expected, it did predict performance-avoidance orientation positively between the latter two measurement points, in line with our expectation, as well as interindividual reward sensitivity negatively. It is also worth noting that sensitivity to punishment and 


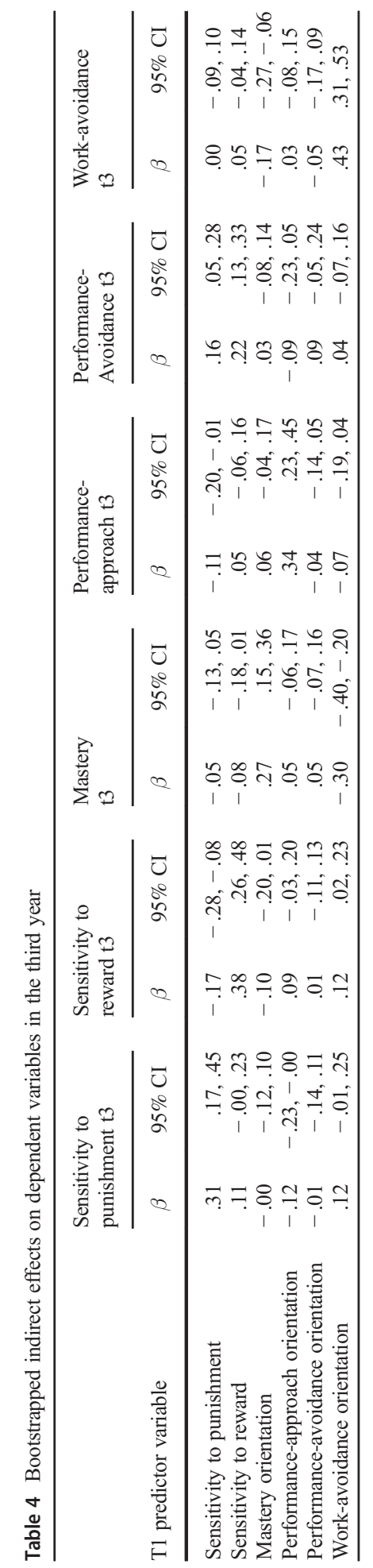


performance-approach orientation correlated negatively at both successive measurement points, and there was a reciprocal, indirect (i.e. from first to third year) negative effect between them. While theoretically meaningful (punishment sensitivity inducing dislike of and withdrawal from competition with peers), this negative relationship is contrary to the results of previous research with adult students (Rawlings et al. 2017), as well as some other previous findings obtained from older students (Bjørnebekk and Diseth 2010; Elliot and Thrash 2002). For students high in punishment sensitivity, adopting a performance-approach orientation has been seen as an approach-to-avoid strategy (Elliot and Thrash 2001). This effect not being observed during the first school years suggests that the strategy may arise over time as one progresses through school, as a way of coping with the anxiety and fear of failure associated with this temperamental sensitivity. More longitudinal research with different age groups is needed to examine this possibility further.

Regarding the relationships between achievement goal orientations, we also found negative reciprocal predictions between mastery and work-avoidance orientations. The finding reflects previous research with older students, where strong negative correlations have been discovered between the two orientations (e.g. King and McInerney 2014; Tuominen-Soini et al. 2011). While it is somewhat striking that academic avoidance should occur already during the first school years, it does reflect the results of some recent person-oriented studies, where small groups of amotivated students have been identified in the early elementary years (e.g. Schwinger, Steinmayr, \& Spinath 2016; see also, Archambault, Eccles, \& Vida 2010). It should be noted, however, that these studies have not generally measured work-avoidance goals or goal orientations explicitly, but rather, have inferred amotivation from low scores in mastery goals or subjective task value. Overall, work-avoidance goals and orientations have been considerably less studied in previous research, in comparison with (dimensions of) mastery and performance goals and orientations (King and McInerney 2014). The negative predictions observed in the present study support the suggestion that including workavoidance orientation may add valuable information to the understanding of students' goal strivings, from the early school years onwards.

Overall, the results offer new knowledge about the development of and connections between temperamental sensitivities and motivation during the early school years. Their stability and early linkages appear educationally important. Interindividual reward sensitivity being negatively related to mastery and positively to performance-avoidance orientation appears particularly noteworthy, given mastery orientation is linked with various educationally and socially adaptive (e.g. Chatzisarantis et al. 2016; Sideridis and Kaplan 2011) and performance-avoidance with maladaptive (e.g. Shin and Ryan 2014; Sideridis 2005) outcomes. High levels of interindividual reward sensitivity manifesting as these connections, especially already at these early stages in students' academic careers, may leave students prone to this sensitivity in an educationally as well as socially disadvantaged position. It is also interesting that interindividual reward sensitivity is positively related to both performance-approach and performance-avoidance orientations, which, while often found to correlate positively (e.g. Pulkka and Niemivirta 2015; Tuominen-Soini et al. 2011), could be considered as fairly different ways of responding to a concern over one's performance relative to others. Interindividual reward sensitivity may induce a proneness for these kinds of performance concerns, and the adoption of either approach or avoidance goals in response may depend, for example, on the relative strength of other temperamental sensitivities (Rawlings et al. 2017), environmental factors, or a combination of these. More research into the mechanisms of these connections is needed. 


\section{Limitations and suggestions for future research}

The study has some limitations. An important aspect to consider is our use of teacher-reports exclusively. Teacher evaluations of students' temperamental sensitivities and motivational orientations illuminate an aspect of the phenomena and their connections, but do not cover them entirely, as outcomes associated with a given temperament do not necessarily generalise across contexts (Wachs and Kohnstamm 2001). The inner states of others have to be inferred from their behaviour (e.g. Dicke, Lüdtke, Trautwein, Nagy, \& Nagy 2012), and as people may behave differently in different contexts, teacher-, parent-, and self-evaluations of some dimensions of temperament (e.g. De Decker et al. 2017; Viljaranta et al. 2015) and achievement goal orientations (e.g. Dicke et al. 2012) have not always been in agreement. Although we have attempted to focus on behavioural expressions of temperamental sensitivities and motivational orientations in our operationalisation, some dimensions may be inherently less "visible" (Kenny and West 2010) than others. For example, accurately judging in others traits that load onto neuroticism (e.g. discomfort with uncertainty and complexity, concern over one's adequacy) has been found challenging (Funder and Dobroth 1987). As these traits characterise also punishment sensitivity, it may follow that its expected relationships were harder for teachers to detect. In future research, utilising multiple informants and examining similarities and differences in their evaluations might give a more comprehensive picture.

However, the way the present results quite closely reflect those obtained from adults' selfevaluations of their temperament and motivation (Rawlings et al. 2017) supports considering teachers' evaluations as fairly accurate representations of their students' actual sensitivities and tendencies. Closeness to the person is seen as greatly improving accuracy of evaluation (Kolar, Funder, \& Colvin 1996; see also, Kenny and West 2010), and as class teachers spend practically every school day in its entirety with their classes, they may be very well acquainted with their students. Also, both temperament and achievement goal orientations remained relatively stable between the second and third years in spite of some change in teachers completing the evaluations, suggesting coherence in the assessment. Finally, also the respective correlations between mastery and performance-approach orientations, and performanceapproach and performance-avoidance orientations resemble those obtained from selfevaluations in previous research with similar age groups (e.g. Bong 2009), suggesting accuracy of the teachers' ratings.

One methodologically challenging issue concerns the possible clustering of responses due to a teacher effect. A larger sample would help in this matter, although the problem remains that in the Finnish educational system, the class sizes during the first school years are often relatively small, due to which the methodological options to deal with this are somewhat limited. Also, a more socio-economically and ethnically diverse and representative sample would enable broader generalisation of the results.

\section{Conclusions}

Our findings provide new knowledge on the stability of and interplay between students' temperamental sensitivities and goal tendencies during the first school years. In teachers' evaluations, students' temperamental sensitivities and achievement goal orientations appear relatively stable, and seem to become linked from an early stage. We see as particularly noteworthy the way interindividual reward sensitivity appears to be associated with 
performance concerns and with a decrease in mastery-oriented strivings. This kind of linking may have long-lasting significance with regard to students' learning and school experiences, and emphasises the importance of an understanding of and responsiveness to students' temperamental sensitivities right from the early school years onwards.

Acknowledgements This research was supported by the Academy of Finland (grant \#279742 to MN) and by the Finnish Cultural Foundation (grant \#181078 to AT). The first author has been funded by a doctoral student position at the University of Helsinki Doctoral Programme in Psychology, Learning and Communication and a personal grant from the Ella \& Georg Ehrnrooth Foundation. The authors wish to thank all students and teachers for participation, the members of the Motivation, Learning, and Well-Being research group for their comments and support, and the anonymous reviewers for their constructive and helpful comments. Open access funding provided by University of Helsinki including Helsinki University Central Hospital.

Open Access This article is distributed under the terms of the Creative Commons Attribution 4.0 International License (http://creativecommons.org/licenses/by/4.0/), which permits unrestricted use, distribution, and reproduction in any medium, provided you give appropriate credit to the original author(s) and the source, provide a link to the Creative Commons license, and indicate if changes were made.

\section{References}

Archambault, I., Eccles, J. S., \& Vida, M. N. (2010). Ability self-concepts and subjective value in literacy: joint trajectories from grades 1 through 12. Journal of Educational Psychology, 102(4), 804-816. https://doi. org/10.1037/a0021075.

Barrera, A. E., \& Schuster, B. (2018). Cross-domain effects of achievement goals: social costs and benefits. European Journal of Psychology of Education, 33(2), 319-336. https://doi.org/10.1007/s10212-017-0333-1.

Bishop, G., Spence, S. H., \& McDonald, C. (2003). Can parents and teachers provide a reliable and valid report of behavioral inhibition? Child Development, 74(6), 1899-1917. https://doi.org/10.1046/j.14678624.2003.00645.x.

Bjørnebekk, G. (2007). Reinforcement sensitivity theory and major motivational and self-regulatory processes in children. Personality and Individual Differences, 43(8), 1980-1990. https://doi.org/10.1016/j. paid.2007.06.010.

Bjørnebekk, G., \& Diseth, Å. (2010). Approach and avoidance temperaments and achievement goals among children. Personality and Individual Differences, 49(8), 938-943. https://doi.org/10.1016/j. paid.2010.07.034.

Bong, M. (2009). Age-related differences in achievement goal differentiation. Journal of Educational Psychology, 101(4), 879-896. https://doi.org/10.1007/978-1-4419-1428-6_804.

Bong, M., Woo, Y., \& Shin, J. (2013). Do students distinguish between different types of performance goals? The Journal of Experimental Education, 81(4), 464 489. https://doi.org/10.1080/00220973.2012.745464.

Carranza, J. A., González-Salinas, C., \& Ato, E. (2013). A longitudinal study of temperament continuity through IBQ, TBAQ and CBQ. Infant Behavior and Development, 36(4), 749-761. https://doi.org/10.1016/j. infbeh.2013.08.002.

Carver, C. S., \& White, T. L. (1994). Behavioral inhibition, behavioral activation, and affective responses to impending reward and punishment. Journal of Personality and Social Psychology, 67(2), 319-333. https://doi.org/10.1037/0022-3514.67.2.319.

Cellar, D. F., Stuhlmacher, A. F., Young, S. K., Fisher, D. M., Adair, C. K., Haynes, S., Twichell, E., Arnold, K. A., Royer, K., Denning, B. L., \& Riester, D. (2011). Trait goal orientation, self-regulation, and performance: a meta-analysis. Journal of Business and Psychology, 26(4), 467-483. https://doi.org/10.1007/s10869-0109201-6.

Chatzisarantis, N. L., Ada, E. N., Bing, Q., Papaioannou, A., Prpa, N., \& Hagger, M. S. (2016). Clarifying the link between mastery goals and social comparisons in classroom settings. Contemporary Educational Psychology, 46, 61-72. https://doi.org/10.1016/j.cedpsych.2016.04.009.

Cloninger, C. R., Svarkic, D. M., \& Przybeck, T. R. (1993). A psychobiological model of temperament and character. Archives of General Psychiatry, 50(12), 975-990.

Cohen, M. X., Weber, B., Schoene-Bake, J., \& Elger, C. E. (2009). Connectivity-based segregation of the human striatum predicts personality characteristics. Nature Neuroscience, 12(1), 32-34. https://doi.org/10.1038 /nn.2228. 
Colder, C. R., \& O'Connor, R. M. (2004). Gray's reinforcement sensitivity model and child psychopathology: laboratory and questionnaire assessment of the BAS and BIS. Journal of Abnormal Child Psychology, 32(4), 435-451. https://doi.org/10.1023/B:JACP.0000030296.54122.b6.

Colder, C. R., Trucco, E. M., Lopez, H. I., Hawk, L. W., Read, J. P., Lengua, L. J., et al. (2011). Revised reinforcement sensitivity theory and laboratory assessment of BIS and BAS in children. Journal of Research in Personality, 45(2), 198-207. https://doi.org/10.1016/j.jrp.2011.01.005.

Corr, P. J. (2013). Approach and avoidance behaviour: multiple systems and their interactions. Emotion Review, 5(3), 285-290. https://doi.org/10.1177/1754073913477507.

Corr, P. J., \& Cooper, A. J. (2016). The reinforcement sensitivity theory of personality questionnaire (RST-PQ): development and validation. Psychological Assessment, 28(11), 1427-1440. https://doi.org/10.1037 /pas0000273.

Corr, P. J., DeYoung, C. G., \& McNaughton, N. (2013). Motivation and personality: a neuropsychological perspective. Social and Personality Psychology Compass, 7(3), 158-175. https://doi.org/10.1111 /spc3.12016.

Covington, M. V. (2000). Goal theory, motivation, and school achievement: an integrative review. Annual Review of Psychology, 51(1), 171-200. https://doi.org/10.1146/annurev.psych.51.1.171.

Crouzevialle, M., \& Butera, F. (2013). Performance-approach goals deplete working memory and impair cognitive performance. Journal of Experimental Psychology. General, 142(3), 666-678. https://doi. org/10.1037/a0029632.

Darnon, C., Dompnier, B., \& Poortvliet, P. M. (2012). Achievement goals in educational contexts: a social psychology perspective. Social and Personality Psychology Compass, 6(10), 760-771. https://doi. org/10.1111/j.1751-9004.2012.00457.x.

De Decker, A., Verbeken, S., Sioen, I., Michels, N., Vervoort, L., Braet, C., \& De Henauw, S. (2017). BIS/BAS scale in primary school children: parent-child agreement and longitudinal stability. Behaviour Change, 34(2), 98-116. https://doi.org/10.1017/bec.2017.8.

Derryberry, D., \& Rothbart, M. K. (1997). Reactive and effortful processes in the organization of temperament. Development and Psychopathology, 9(4), 633-652.

Derryberry, D., Reed, M. A., \& Pilkenton-Taylor, C. (2003). Temperament and coping: advantages of an individual differences perspective. Development and Psychopathology, 15(4), 1049-1066. https://doi. org/10.1017/S0954579403000439.

DeYoung, C. G. (2010). Discussion on 'Automatic and controlled processes in behavioural control: Implications for personality psychology’ by Corr. Open peer commentary: Mapping personality traits onto brain systems: BIS, BAS, FFFS and beyond. European Journal of Personality, 24(5), 404-407. https://doi.org/10.1002 /per.780.

Dicke, A., Lüdtke, O., Trautwein, U., Nagy, G., \& Nagy, N. (2012). Judging students' achievement goal orientations: are teacher ratings accurate? Learning and Individual Differences, 22(6), 844-849. https://doi.org/10.1016/j.lindif.2012.04.004.

Dweck, C. S., \& Leggett, E. L. (1988). A social-cognitive approach to motivation and personality. Psychological Review, 95(2), 256-273. https://doi.org/10.1037/0033-295X.95.2.256.

Elliot, A. J., \& Covington, M. V. (2001). Approach and avoidance motivation. Educational Psychology Review, 13(2), 73-92. https://doi.org/10.1023/A:1009009018235.

Elliot, A. J., \& Hulleman, C. S. (2017). Achievement goals. In A. J. Elliot, C. S. Dweck, \& D. S. Yeager (Eds.), Handbook of competence and motivation. Theory and application (Second ed., pp. 43-60). New York: The Guildford Press.

Elliot, A. J., \& Thrash, T. M. (2001). Achievement goals and the hierarchical model of achievement motivation. Educational Psychology Review, 13(2), 139-156. https://doi.org/10.1023/A:1009057102306.

Elliot, A. J., \& Thrash, T. M. (2002). Approach-avoidance motivation in personality: approach and avoidance temperaments and goals. Journal of Personality and Social Psychology, 82(5), 804-818. https://doi. org/10.1037/0022-3514.82.5.804.

Elliot, A. J., \& Thrash, T. M. (2010). Approach and avoidance temperament as basic dimensions of personality. Journal of Personality, 78(3), 865-906. https://doi.org/10.1111/j.1467-6494.2010.00636.x.

Finnish National Agency for Education. (2017). Finnish Education in a Nutshell. Ministry of Education and Culture. Retrieved 23 February 2018, from http://www.oph.fi/download/146428_Finnish_Education_in_a_ Nutshell.pdf.

Funder, D. C., \& Dobroth, K. M. (1987). Differences between traits: properties associated with interjudge agreement. Journal of Personality and Social Psychology, 52(2), 409-418. https://doi.org/10.1037/00223514.52.2.409.

Gonçalves, T., Niemivirta, M., \& Lemos, M. S. (2017). Identification of students' multiple achievement and social goal profiles and analysis of their stability and adaptability. Learning and Individual Differences, 54, 149-159. https://doi.org/10.1016/j.lindif.2017.01.019. 
Gray, J. A., \& McNaughton, N. (2003). The neuropsychology of anxiety. Oxford: Oxford University Press.

Hair, J. F., Jr., Hult, G. T. M., Ringle, C. M., \& Sarstedt, M. (2014). A primer on partial least squares structural equation modeling (PLS-SEM). Sage Publications.

Henseler, J., Ringle, C. M., \& Sarstedt, M. (2015). A new criterion for assessing discriminant validity in variancebased structural equation modeling. Journal of the Academy of Marketing Science, 43(1), 115-135. https://doi.org/10.1007/s11747-014-0403-8.

Hirvonen, R., Aunola, K., Alatupa, S., Viljaranta, J., \& Nurmi, J. E. (2013). The role of temperament in children's affective and behavioral responses in achievement situations. Learning and Instruction, 27, 21-30. https://doi.org/10.1016/j.learninstruc.2013.02.005.

Hirvonen, R., Torppa, M., Nurmi, J. E., Eklund, K., \& Ahonen, T. (2016). Early temperament and age at school entry predict task avoidance in elementary school. Learning and Individual Differences, 47, 1-10. https://doi.org/10.1016/j.lindif.2015.12.012.

Hulleman, C. S., Schrager, S. M., Bodmann, S. M., \& Harackiewicz, J. M. (2010). A meta-analytic review of achievement goal measures. Psychological Bulletin, 136(3), 422-449. https://doi.org/10.1037/a0018947.

Jõgi, A., Kikas, E., Lerkkanen, M., \& Mägi, K. (2015). Cross-lagged relations between math-related interest, performance goals and skills in groups of children with different general abilities. Learning and Individual Differences, 39, 105-113. https://doi.org/10.1016/j.lindif.2015.03.018.

Kagan, J. (1980). Perspectives on continuity. In O. G. Brim \& J. Kagan (Eds.), Constancy and change in human development (pp. 26-74). Cambridge, MA: Harvard University Press.

Kenny, D. A., \& West, T. V. (2010). Similarity and agreement in self- and other perception: a meta-analysis. Personality and Social Psychology Review, 14(2), 196-213. https://doi.org/10.1177/1088868309353414.

King, R. B. (2014). The dark cycle of work avoidance goals and disengagement: a cross-lagged analysis. Psychological Studies, 59(3), 268-277. https://doi.org/10.1007/s12646-014-0267-5.

King, R. B., \& McInerney, D. M. (2014). The work avoidance goal construct: examining its structure, antecedents, and consequences. Contemporary Educational Psychology, 39(1), 42-58. https://doi. org/10.1016/j.cedpsych.2013.12.002.

Kingsbury, A., Coplan, R. J., Weeks, M., \& Rose-Krasnor, L. (2013). Covering all the BAS's: a closer look at the links between BIS, BAS, and socio-emotional functioning in childhood. Personality and Individual Differences, 55(5), 521-526. https://doi.org/10.1016/j.paid.2013.04.021.

Kolar, D. W., Funder, D. C., \& Colvin, C. R. (1996). Comparing the accuracy of personality judgments by the self and knowledgeable others. Journal of Personality, 64(2), 311-337. https://doi.org/10.1111/j.14676494.1996.tb00513.x.

Lepola, J. (2004). The role of gender and reading competence in the development of motivational orientations from kindergarten to grade 1. Early Education and Development, 15(2), 215-240. https://doi.org/10.1207 /s15566935eed1502_5.

Mägi, K., Lerkkanen, M., Poikkeus, A., Rasku-Puttonen, H., \& Kikas, E. (2010). Relations between achievement goal orientations and math achievement in primary grades: a follow-up study. Scandinavian Journal of Educational Research, 54(3), 295-312. https://doi.org/10.1080/00313831003764545.

Nicholls, J. G. (1984). Achievement motivation: conceptions of ability, subjective experience, task choice, and performance. Psychological Review, 91(3), 328-346. https://doi.org/10.1037/0033-295X.91.3.328.

Nicholls, J. G. (1989). The competitive ethos and democratic education. Harvard University Press.

Nicholls, J. G., Patashnick, M., \& Nolen, S. B. (1985). Adolescents' theories of education. Journal of Educational Psychology, 77(6), 683-692. https://doi.org/10.1037//0022-0663.77.6.683.

Niemivirta, M. (2002). Motivation and performance in context: the influence of goal orientations and instructional setting on situational appraisals and task performance. Psychologia, 45(4), 250-270. https://doi. org/10.2117/psysoc.2002.250.

Niemivirta, M., Pulkka, A.-T., Tapola, A., \& Tuominen, H. (2019). Achievement goal orientations: a personoriented approach. In K. A. Renninger \& S. E. Hidi (Eds.), The Cambridge handbook of motivation and learning (pp. 566-616). Cambridge, UK: Cambridge University Press.

Pintrich, P. R. (2000). An achievement goal theory perspective on issues in motivation terminology, theory, and research. Contemporary Educational Psychology, 25(1), 92-104. https://doi.org/10.1006/ceps.1999.1017.

Poortvliet, P. M. (2012). Harming others' task-related efforts: the distinct competitive effects of ranking information on performance and mastery goal individuals. Social Psychology, 44(6), 373-379. https://doi. org/10.1027/1864-9335/a000161.

Poortvliet, P. M., \& Darnon, C. (2010). Toward a more social understanding of achievement goals: the interpersonal effects of mastery and performance goals. Current Directions in Psychological Science, 19(5), 324-328. https://doi.org/10.1177/0963721410383246.

Poropat, A. E. (2014). A meta-analysis of adult-rated child personality and academic performance in primary education. British Journal of Educational Psychology, 84(2), 239-252. https://doi.org/10.1111/bjep.12019. 
Pulkka, A.-T., \& Niemivirta, M. (2015). The relationships between adult students' achievement goal orientations, self-defined course goals, course evaluations, and performance. Journal for Educational Research Online, 7(3), 28-53. https://doi.org/10.1016/j.ijer.2013.03.015.

Rawlings, A. M., Tapola, A., \& Niemivirta, M. (2017). Predictive effects of temperament on motivation. International Journal of Educational Psychology, 6(2), 148-182. https://doi.org/10.17583/ijep.2017.2414.

Rothbart, M. K. (2007). Temperament, development, and personality. Current Directions in Psychological Science, 16(4), 207-212. https://doi.org/10.1111/j.1467-8721.2007.00505.x.

Rothbart, M. K., \& Hwang, J. (2005). Temperament and the development of competence and motivation. In A. J. Elliot \& C. S. Dweck (Eds.), Handbook of competence and motivation (pp. 167-185). New York, N.Y: The Guildford Press.

Roubinov, D. S., Hagan, M. J., Boyce, W. T., Essex, M. J., \& Bush, N. R. (2017). Child temperament and teacher relationship interactively predict cortisol expression: the prism of classroom climate. Development and Psychopathology, 29(5), 1763-1775. https://doi.org/10.1017/S0954579417001389.

Sanchez, G. (2013). PLS path modeling with R. Berkeley: Trowchez Editions. http://www.gastonsanchez. com/PLS Path Modeling with R.

Sanchez, G., Trinchera, L., \& Russolillo, G. (2015). plspm: tools for partial least squares path modeling (PLSPM). R package version 0.4.7. https://CRAN.R-project.org/package=plspm

Sarstedt, M., Ringle, C. M., \& Hair, J. F. (2017). Partial least squares structural equation modeling. In Handbook of market research, (pp. 1-40). Springer International Publishing. https://oi.org/10.1007/978-3-319-055428 15-1.

Schwinger, M., Steinmayr, R., \& Spinath, B. (2016). Achievement goal profiles in elementary school: antecedents, consequences, and longitudinal trajectories. Contemporary Educational Psychology, 46, 164-179. https://doi.org/10.1016/j.cedpsych.2016.05.006.

Senko, C. (2016). Achievement goal theory: a story of early promises, eventual discords, and future possibilities. In K. R. Wentzel \& D. B. Miele (Eds.), Handbook of motivation at school (2nd ed., pp. 75-95). New York, N.Y: Routledge Ltd - M.U.A.

Senko, C., \& Dawson, B. (2017). Performance-approach goal effects depend on how they are defined: Metaanalytic evidence from multiple educational outcomes. Journal of Educational Psychology, 109(4), 574 598. https://doi.org/10.1037/edu0000160.

Senko, C., \& Tropiano, K. L. (2016). Comparing three models of achievement goals: goal orientations, goal standards, and goal complexes. Journal of Educational Psychology, 108(8), 1178-1192. https://doi. org/10.1037/edu0000114.

Senko, C., Hulleman, C. S., \& Harackiewicz, J. M. (2011). Achievement goal theory at the crossroads: old controversies, current challenges, and new directions. Educational Psychologist, 46(1), 26-47. https://oi. org/10.1080/00461520.2011.538646.

Shin, H., \& Ryan, A. M. (2014). Friendship networks and achievement goals: an examination of selection and influence processes and variations by gender. Journal of Youth and Adolescence, 43(9), 1453-1464. https://doi.org/10.1007/s10964-014-0132-9.

Sideridis, G. D. (2005). Goal orientation, academic achievement, and depression. Journal of Educational Psychology, 97(3), 366-375. https://doi.org/10.1037/0022-0663.97.3.366.

Sideridis, G. D., \& Kaplan, A. (2011). Achievement goals and persistence across tasks: the roles of failure and success. The Journal of Experimental Education, 79(4), 429-451. https://doi.org/10.1080 /00220973.2010.539634.

Skaalvik, E. (2018). Mathematics anxiety and coping strategies among middle school students: relations with students' achievement goal orientations and level of performance. Social Psychology of Education, 21(3), 709-723. https://doi.org/10.1007/s11218-018-9433-2.

Slobodskaya, H. R., \& Kozlova, E. A. (2016). Early temperament as a predictor of later personality. Personality and Individual Differences, 99, 127-132. https://doi.org/10.1016/j.paid.2016.04.094.

Slobodskaya, H. R., \& Kuznetsova, V. B. (2013). The role of reinforcement sensitivity in the development of childhood personality. International Journal of Behavioral Development, 37(3), 248-256. https:/doi. org/10.1177/0165025413475895.

Stekhoven, D. J. (2013). missForest: nonparametric missing value imputation using random forest. R package version 1.4.

Stekhoven, D. J., \& Bühlmann, P. (2011). missForest - non-parametric missing value imputation for mixed-type data. Bioinformatics, 28(1), 112-118. https://doi.org/10.1093/bioinformatics/btr597.

Tapola, A., \& Niemivirta, M. (2008). The role of achievement goal orientations in students' perceptions of and preferences for classroom environment. The British Journal of Educational Psychology, 78(2), 291-312. https://doi.org/10.1348/000709907X205272. 
Torrubia, R., Ávila, C., Moltó, J., \& Caseras, X. (2001). The sensitivity to punishment and sensitivity to reward questionnaire (SPSRQ) as a measure of Gray's anxiety and impulsivity dimensions. Personality and Individual Differences, 31(6), 837-862. https://doi.org/10.1016/S0191-8869(00)00183-5.

Tuominen-Soini, H., Salmela-Aro, K., \& Niemivirta, M. (2011). Stability and change in achievement goal orientations: a person-centered approach. Contemporary Educational Psychology, 36(2), 82-100. https://doi. org/10.1016/j.cedpsych.2010.08.002.

Tuominen-Soini, H., Salmela-Aro, K., \& Niemivirta, M. (2012). Achievement goal orientations and academic well-being across the transition to upper secondary education. Learning and Individual Differences, 22(3), 290-305. https://doi.org/10.1016/j.lindif.2012.01.002.

Urošević, S., Collins, P., Muetzel, R., Lim, K., \& Luciana, M. (2012). Longitudinal changes in behavioral approach system sensitivity and brain structures involved in reward processing during adolescence. Developmental Psychology, 48(5), 1488-1500. https://doi.org/10.1037/a0027502.

Viljaranta, J., Aunola, K., Mullola, S., Virkkala, J., Hirvonen, R., Pakarinen, E., \& Nurmi, J. (2015). Children's temperament and academic skill development during first grade: teachers' interaction styles as mediators. Child Development, 86(4), 1191-1209. https://doi.org/10.1111/cdev.12379.

Wachs, T. D., \& Kohnstamm, G. A. (2001). The bidirectional nature of temperament-context links. In T. D. Wachs \& G. A. Kohnstamm (Eds.), Temperament in context (pp. 171-189). GB: Psychology Press.

Publisher's note Springer Nature remains neutral with regard to jurisdictional claims in published maps and institutional affiliations.

Anna Maria Rawlings. Faculty of Educational Sciences, University of Helsinki, Helsinki, Finland. E-mail: anna.rawlings@helsinki.fi

Current themes of research:

Research on individual differences in temperamental sensitivities and student motivation (e.g. achievement goal orientations, interest, effort), their relationship and its outcomes (e.g. on achievement, stress).

Most relevant publications in the field of Psychology of Education:

Rawlings, A. M., Tapola, A., \& Niemivirta, M. (2017). Predictive effects of temperament on motivation. International Journal of Educational Psychology, 6(2), 148-182.

Anna Tapola. Faculty of Educational Sciences, University of Helsinki, Helsinki, Finland. E-mail: anna.tapola@helsinki.fi

Current themes of research:

Research on student motivation, interest, and learning. Individual differences in students' motivational tendencies (e.g. achievement goal orientations and individual interest), situational states (situational interest and selfefficacy), and their relationship. Interactionism, person $\times$ context interactions influencing students' motivation and academic outcomes.

Most relevant publications in the field of Psychology of Education:

Niemivirta, M., Pulkka, A.-T., Tapola, A., \& Tuominen, H. (2019). Achievement goal orientations: a personoriented approach. In K. A. Renninger, \& S. E. Hidi (Eds.), The Cambridge handbook of motivation and learning (pp. 566-616). Cambridge: Cambridge University Press.

Nuutila, K., Tuominen, H., Tapola, A., Vainikainen, M.-P., \& Niemivirta, M. (2018). Consistency, longitudinal stability, and predictions of elementary school students' task interest, success expectancy, and performance in mathematics. Learning and Instruction, 56, 73-83. 
Rawlings, A. M., Tapola, A., \& Niemivirta, M. (2017). Predictive effects of temperament on motivation. International Journal of Educational Psychology, 6, 148-182.

Korhonen, J., Tapola, A., Linnanmäki, K., \& Aunio, P. (2016). Gendered pathways to educational aspirations: the role of academic self-concept, school burnout, achievement and interest in mathematics and reading. Learning and Instruction, 46, 21-33.

Tapola, A., Jaakkola, T., \& Niemivirta, M. (2014). The influence of achievement goal orientations and task concreteness on situational interest. Journal of Experimental Education, 82, 455-479.

Markku Niemivirta. Faculty of Educational Sciences, University of Oslo, Oslo, Norway, and Faculty of Educational Sciences, University of Helsinki, Helsinki, Finland. E-mail: markku.niemivirta@iped.uio.no; markku.niemivirta@helsinki.fi

Current themes of research:

Developmental relationships between motivation, learning, and well-being. Situational dynamics between motivation and performance. Individual and contextual predictors of motivation, particularly in mathematics and in relation to gender.

Most relevant publications in the field of Psychology of Education:

Niemivirta, M., Pulkka, A.-T., Tapola, A., \& Tuominen, H. (2019). Achievement goal orientations: a personoriented approach. In K. A. Renninger, \& S. E. Hidi (Eds.), The Cambridge handbook of motivation and learning (pp. 566-616). Cambridge: Cambridge University Press.

Nuutila, K., Tuominen, H., Tapola, A., Vainikainen, M.-P., \& Niemivirta, M. (2018). Consistency, longitudinal stability, and predictions of elementary school students' task interest, success expectancy, and performance in mathematics. Learning and Instruction, 56, 73-83.

Tuominen-Soini, H., Salmela-Aro, K. \& Niemivirta, M. (2011). Stability and change in achievement goal orientations: a person-centred approach. Contemporary Educational Psychology, 36, 82-100.

Aunio, P. \& Niemivirta, M. (2010). Predicting children's mathematical performance in grade one by early numeracy. Learning and Individual Differences, 20(5), 427-435.

Boekaerts, M. \& Niemivirta, M. (2000). Self-regulated learning: finding a balance between learning- and egoprotective goals. In M. Boekaerts, P. R Pintrich, \& M. Zeidner (Eds.), Handbook of Self- Regulation (pp. 417-450). San Diego, CA: Academic Press.

\section{Affiliations}

\section{Anna Maria Rawlings ${ }^{1} \cdot$ Anna Tapola $^{1} \cdot$ Markku Niemivirta ${ }^{1,2}$}

Anna Tapola

anna.tapola@helsinki.fi

1 Faculty of Educational Sciences, University of Helsinki, Helsinki, Finland

2 Faculty of Educational Sciences, University of Oslo, Oslo, Norway 